\title{
GAIA Level 1b Prenatally Diagnosed Congenital Microcephaly
}

National Cancer Institute

\section{Source}

National Cancer Institute. GAIA Level 1b Prenatally Diagnosed Congenital Microcephaly. NCI Thesaurus. Code C128763.

GAIA Level $1 \mathrm{~b}$ Prenatally Diagnosed Cong enital Microcephaly is defined by three criteria: first, the fetus is at least 24 weeks gestational age (GA) based on uncertain last menstrual period (LMP) date with a 2nd trimester ultrasound (US) scan; second, a head circumference (HC) measurement either 2 standard deviations (SD) below the mean or less than the third percentile according to fetal US examination, using appropriate, standardized reference charts according to GA and gender for the population (e.g. WHO growth reference charts if GA greater than or equal to 37 weeks and Interg rowth-21st reference charts for GA 24-36 weeks); third, confirmation of microcephaly (i.e., HC 2 SD below the mean or less than 3\%) in the fetus by either at least one additional US after 24 weeks that occurs at least one week after the first US, OR confirmation of microcephaly by HC measurement with a standard tape measure at either birth or autopsy. 